Muravskaya $O$. Choral polonaises $O$. Kozlovsky in the context of the tradition of Alexander's empire. The article is devoted to the poetics of choral polonaises O. Kozlovsky considered in line with the specifics of russian musical and historical tradition of the turn of XVIII-XIX centuries and stylistic qualities of Alexander's empire.

Keywords: empire, Alexander the empire, the imperial court culture, polonaise, choral polonaise, creativity O. Kozlovsky.

Стаття надійцла до редакції 13.04.2016

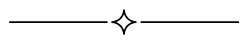

УДК $78.03+781.6$

\author{
Ю. Грибиненко
}

\title{
СОНАТА ДЛЯ ВИОЛОНЧЕЛИ И ФОРТЕПИАНО № 1 АЛЬФРЕДА ШНИТКЕ В КОНТЕКСТЕ ЭВОЛЮЦИИ АВТОРСКОГО СТИЛЯ
}

Статья посвящена рассмотрению образно-смысловых, композиционно-драматургических и жанрово-стилевых особенностей первой виолончельной сонаты А. Шнитке в контексте эволюции его композиторского мышления. Акцентируется внимание на драматургических приемах, спеиифике и диапазоне языковых средств, на особенностях трактовки выразительных возможностей инструментов, на образном строе сочинения, как этапного на новом витке эволюции авторского стиля композитора.

Ключевые слова: виолончельная соната, А. Шнитке, интонационное единство, моностилистика, пауза.

Первая виолончельная соната (1978), посвященная Наталии Гутман ${ }^{1}$, стоит в центре камерно-инструментального творчества А. Шнитке. Ее отделяет десятилетие от написания Второй скрипичной сонаты, девять лет от Первой фортепианной и шестнадцать от Второй виолончельной. Сам композитор, неоднократно высказывавшийся по поводу своего творчества, дал следующую характеристику своей первой виолончельной сонате, впервые прозвучавшей на авторском вечере А. Шнитке 29 марта 1979 года: «Это очень простое сочинение, и никаких особенных технологических замыслов у меня не было. Единственное, что обращает на себя внимание - то, что мне

\footnotetext{
${ }^{1}$ Как известно, кроме сонаты, композитор посвятил этой исполнительнице (как называл ее С. Рихтер, «цветок с корнями дуба») также свой концерт для виолончели с оркестром № 1 (1986).
}

(C) Грибиненко Ю., 2016 
сейчас интересно - это попытка найти такой интонационный язык, который мог бы оборачиваться как тональным, так и нетональным. Этим я хотел достичь не только контраста, но и интонационной взаимосвязи» [5, с. 86].

Данное произведение было создано в тот период творческой деятельности композитора, который С. Савенко назвала «новой зрелостью» [2], а В. Холопова охарактеризовала как период «новой простоты», «тихой музыки», «мемориалов» [4, с. 24]. Трагические события, произошедшие в личной жизни композитора, заставили его посмотреть на многое иными глазами, задуматься о «вечных» вопросах жизни и смерти. Творческим кредо этого этапа можно назвать «потребность сказать просто о сложном, не утратив глубины» [2, с. 40], а естественность, лиризм, эмоциональная открытость стали характерными чертами практически всех музыкальных произведений этого этапа, сделав язык А. Шнитке более доступным. С. Савенко подчеркивает, что такие поиски композитора в новом направлении характерны не только для него, но и для ряда других отечественных и зарубежных композиторов. «Видимо, - пишет С. Савенко, - это нынешнее направление музыки отражает одну из существенных потребностей искусства XX века» [2, с. 42].

В отличие от остальных сонат композитора ${ }^{1}$, написанных ранее, первая виолончельная строже, сдержаннее, в ней нет острой экспрессии, большого диапазона контрастов, характерного для композитора образно-эмоционального противостояния, связанного с поэтикой конфликта. Той поэтикой, которая ведет к предельному заострению противоречий при одновременном использовании нескольких стилистических (жанрово-стилистических) комплексов. В этой же сонате заметнее, чем в других, образное и интонационное единство. Здесь нет полярной противоположности стилистических пластов. Исследователи творчества А. Шнитке отмечают, что «стилистические переходы и оттенки здесь (в виолончельной сонате. - Ю. Г.) подчинены единой интонационной логике - это, думается, воистину новая моностилистика» [2, с. 41].

Важной отличительной особенностью сонаты является ее большое образное и интонационное единство, которое достигается благодаря

${ }^{1}$ Напомним, что жанр сонаты оказался достаточно востребованным в творчестве А. Шнитке. Кроме двух виолончельных сонат композитором были созданы четыре скрипичные сонаты (1955, 1963, 1968, 1994 гг.), а также три фортепианные $(1987,1990$, 1992 гг.). 
использованию тематических звукоарок и сквозных моноинтонаций. Драматургия произведения сочетает черты конфликтности и медитативности. Первая проявляется в противостоянии трех извечных категорий: индивидуальное человеческое сознание борется с негативным миром реальности и стремится к духовности «как высшей гармонии и красоте человека» [3, с. 140]. Медитативность - драматургия состояния, образная статика, пребывание в определенном модусе - характерна для крайних частей сонаты и проявляется в замедленном течении времени, в повышенном внимании к деталям, значение которых возрастает, в непрерывности и неизменности потока. Хотя эта константность может привести и к появлению новых элементов и к качественному сдвигу, но не в «событийной», а в образной эмоционально-психологической сфере.

Трехчастная композиция сонаты контрастна (Largo - Presto Largo) и в то же время объединена не только принципом attacca, но и интонационным комплексом «c - $e(e s)-g »$, который, по мнению В. Сумароковой, является центральным элементом Виолончельной сонаты [3, с. 143]. Музыкальная архитектоника произведения сочетает принципы одночастности и цикличности, что проявляется не только в вышеуказанных чертах, но и в опоре на симметричные построения, арочность, на принцип «интонационного прорастания» [3, c. 143]. Все это заставляет нас воспринимать сонату как драму сквозного развития: «...напряженная мысль первой части, как бы временно прерываясь вторжением второй части, подхватывается и достигает кульминации в финале...» [4, с. 138].

Небольшая по размерам первая часть - емкая и лаконичная совмещает функции пролога и сонатной экспозиции. Основу Largo составляют три тематических элемента. Первый, открывающий сочинение, это речитативная каденция виолончели, которая является образным воплощением «рефлектирующего индивидуального сознания» [4, с. 138], «рефлектирующей личности, индивидуальности с богатым внутренним миром, который вбирает в себя все духовные ценности человечества» [3, с. 144]. С этими характеристиками нельзя не согласиться, тем более что типичное сочетание жанров речитатива и каденции является для А. Шнитке средоточием индивидуально-личностного начала, и «голос» виолончели лишь еще раз подчеркивает это. Знаменательно, что подобное жанровое сочетание характерно для разработочных разделов «слитно-циклических» форм (термин В. Холоповой) композитора. Использование данного при- 
ема в начале композиции позволяет А. Шнитке переставить акценты: теперь индивидуальное сознание - «главный герой» музыкального действия. Тема-монолог широкого дыхания охватывает большой диапазон звучания. Ее мелодика основана на чередовании терцовых, секундовых соотношений с ходами на широкие интервалы (ноны, сексты) и постоянном басовом голосе (выдержанные ноты большой, а впоследствии и малой октавы $-c, d)$.

Второй тематический элемент выступает в качестве «чужого слова»: это квазицитата, воспроизводящая историко-стилистическую модель прошлого - тема «золотого хода валторн». Наряду с третьим тематическим элементом - хоралом - первые два являются воплощением объективного, внеличностного начала. Однако современная действительность все же вторгается в этот идеальный мир, полный гармонии. И эта, характерная для творчества А. Шнитке, мысль подтверждается проникновением диссонантности в тему «золотого хода». Ее третье проведение атонально, контуры размыты, что говорит о невозможности включения «идеала прошлого» в современную художественную модель мира. Восемь тактов педальной ноны, на фоне которой проходила тема «золотого хода», сменяются выдержанными секундами в партии рояля. Нона виолончели же становится сильной долей фигуры, напоминающей опорную формулу баса, часто использующуюся в джазовых пьесах.

Первая фаза изложения заканчивается звучанием третьего тематического элемента - хорала, вступившего после такта тишины. Звучание на одной педали, медленное «сползание» баса, тритоновое соотношение двух последних аккордов $(g-E s-\underline{F-H})$ придают ему черты мрачности, неотвратимости.

Во второй фазе части (росо а poco agitato) ведущая роль принадлежит виолончели, а фортепиано звучит лишь в двух тактах. Речитатив, начинающий Largo, здесь видоизменен: во-первых, в нем своеобразно синтезируются основные тематические элементы; вовторых, сам речитатив жанрово переосмыслен и превращается из монолога в «монологический хор» (термин С. Савенко). Предпосылки к такому развитию темы были заложены в ней изначально - вспомним басовый голос в экспозиционном изложении. «Выразительность этого приема основана на парадоксальном «умножении» монологической линии, которая по своей природе едина - это голос героя» [3, с. 145]. Удвоенная мелодия виолончели с ведущим интервалом уменьшенной октавой, звучащая на фоне баса $\left(c, g\right.$, а далее $\left.\frac{c}{g}\right)$ несет 
в себе двоякий смысл: «с одной стороны, количественное усиление, заостряющее экспрессию, поскольку возникает множественный отпечаток, эхо - но не физическое, угасающее, а психологическое, возрастающее, будто звучащие голоса сознания. С другой стороны, наслоение линий нивелирует их интонационную индивидуальность и в результате артикулированная речь перерастает в крик немоты» [3, c. 145]. Иными словами, в этом эпизоде высказывается сомнение в возможности любого монолога, поскольку «рефлектирующее индивидуальное сознание» расколото и неслиянно.

Тему «золотого хода», которая стала прерогативой героя, сменяет хорал, но его тут же перебивает pizzicato виолончели. В заключительных аккордах части сопоставляются стабильность, воплощенная созвучием $G$-dur, и ее нарушение - в виде аккордов с уменьшенной октавой.

Вторая часть - Presto - своим появлением вносит ощутимый контраст, поскольку в образном отношении противопоставляет себя предыдущей части. Это вторжение современной действительности, постепенно затягивающей героя в страшный враждебный водоворот реальных событий. По словам автора, Presto синтезирует в себе черты скерцо и сонаты. Знаменательно, что скерцо своей механистичностью близко по характеру токкатным «злым» скерцо Д. Шостаковича. Образ враждебного мира, затягивающего в свой жуткий водоворот все живое, создается при помощи принципа полиостинатности, которая состоит из двух несовпадающих слоев, отмеченных авторской ремаркой: восемь раз повторяющиеся тринадцать тактов виолончели накладываются на шестнадцатитактовый период в партии фортепиано. Кроме этого во второй части можно обнаружить черты джазовой импровизации, ростки которой появлялись еще в первой части.

Благодаря отсутствию контраста между главной и побочной темами сонатность отходит на второй план. Основная тема части представляет собой остинатный мотив, построенный по типу спирали, который в своем развитии охватывает все больший диапазон. Ядро его составляет тема-круг, для которой характерны секундовые интонации, структурная симметрия, ротационный тип мелодики, что придает теме сходство с музыкально-риторической фигурой circulatio. Побочная тема формируется постепенно из «глубоких» акцентированных октав в партии фортепиано. Постепенно них мягко накладывается лейтгармония части - уменьшенный септаккорд, меняющий свое звуковысотное положение каждые четыре такта. Усложнение 
гармонической вертикали приводит к появлению кластеров, звучащих в более высоком регистре на оттенке $\boldsymbol{m f}$, что привносит в настроение части резкость и нервозность. В следующем этапе развития тема-круг звучит и в партии виолончели, и в партии фортепиано. Интересно то, что она дается одновременно в трех временных измерениях и в постоянном динамическом нарастании:

\begin{tabular}{|c|c|c|c|}
\hline голоса & \multicolumn{3}{|c|}{ Длительности } \\
\hline 1 & $\boldsymbol{\delta}$ & $\boldsymbol{\delta}$ & $\delta$ \\
\hline 2 & $\mathbf{o}$ & $\boldsymbol{\delta}$ & $\delta$ \\
\hline 3 & $\delta$ & $\delta$ & $\delta$ \\
\hline цифры & 5 & 6 & 7 \\
\hline динам. оттенки & $\boldsymbol{F}$ & $\boldsymbol{f f f f f}$ & $\boldsymbol{m f}$ \\
\hline
\end{tabular}

Глиссандирующие квинты у виолончели сменяются размашистыми ходами, охватывающими диапазон двух октав. От темы-круга, после ее кульминационного проведения, остается лишь контур в партии виолончели в виде ротационного движения. На фоне этой остинатной фигуры звучит канон на тему речитатива из первой части, проходящий здесь в увеличении и в обращении.

Начиная с ц. 11 вновь происходит обмен музыкальным материалом. Perpetum mobile звучит в партии фортепиано, совмещая в себе собственно тему-круг и размашистые ходы, строящиеся на тех же звуках, что и собственно тема. В партию виолончели возвращается начальная фраза из основного мотива первой части, поданная здесь в токкатной манере. Заключительный раздел, с одной стороны, суммирует предыдущий этап развития, а с другой - подготавливает новый. Неожиданно тихо звучат, будто разорванные, фразы речитатива (из первой части), проходящие на фоне полигармонических сочетаний, а также на фоне выдержанной ноны (из первой части). Особо выделяется lamento'зная интонация нисходящей малой секунды, вычлененная из речитатива. Ее звучание напряжено и одиноко в высоком регистре виолончели и постепенно замирает. После такта паузы начинается средняя часть - или эпизод разработки - это вальс, гротескный по характеру - в духе вальсов Д. Шостаковича. В его основе лежит «антагонистический» диалог двух инструментов [3, с. 146]. На наш взгляд, это скорее диалог двух тематических комплексов, отображающих две эмоционально-образные сферы: выразительных речитативных фраз (индивидуальное сознание) и застывших, подчас резких полигармонических сочетаний (реальный мир). Генеральная 
кульминация части в точке золотого сечения продолжает эту линию, но в гипертрофированном виде. Так, например, «взлетающая» экспрессивная фраза в партии виолончели занимает четыре октавы. Ее пик построен на целотоновых ходах, замаскированных в трелях, исполняющихся форсированным звуком, будто на грани возможностей. Также восходящая линия в партии фортепиано, но по тритонам, приводит к акцентированному кластеру-педали - две кварты на расстоянии тритона.

Реприза начинается, как и экспозиция, на pp, но прием sul ponticello вносит в характер вернувшейся темы-круга безжизненность. После канонического проведения видоизмененной темы речитатива из первой части появляется вальсовый эпизод, в котором не участвует виолончель. Она присоединится лишь спустя семь тактов с давно не звучавшей темой perpetum mibile. Словно завоевывая свои потерянные позиции, тема-круг вновь пройдет в трех временных измерениях, подчеркивая этим свою неотвратимость. Форма канона лишь усиливает чувство бега по замкнутому кругу. Вновь уступив место речитативу виолончели, поддерживаемому квартовыми ходами в партии фортепиано, тема-круг вернется в большом, токкатного плана эпизоде, с неоднократно повторяющимся «глубоким» созвучием $a-e s-a$. Круг все больше сужается, даже создается впечатление, что композитор хочет свернуть тему в унисон, но звуковой поток уносится в бесконечность. Еще одна попытка прорваться завершается безрезультатно, о чем свидетельствует кластер fff в партии фортепиано. С ц. 29 начинается кода, приводящая к третьей части, которая является драматургическим и структурным продолжением Presto.

Весь заключительный раздел второй части, по сути, это каденция виолончели, так как в партии фортепиано на протяжении тридцати девяти тактов поддерживается с помощью лиги и педали кластер, завершающий репризу. Каденция синтезирует в себе тематические элементы, звучавшие ранее: пиццикатные аккорды (из заключения первой части) и тему perpetum mobile. «Кричащая», напряженная, в третьей октаве, она постепенно сужается после небольшого расширения, прерывается паузами и замолкает.

Третья часть Largo начинается на предельном уровне напряжения как естественное продолжение предыдущего этапа развития. С ц. 12 начинается раздел, который можно считать репризой первой части. Кроме этого он еще несет нагрузку коды всего цикла, в которой прозвучат темы из первой и второй частей сонаты. 
В начальном разделе на фоне хоральных аккордов звучит акцентированная на каждой доле в высоком регистре интонация нисходящей малой секунды. Обычно трактующаяся как lamento, в данном контексте она приобретает протестующий характер - это крик в его экспрессионистской трактовке, говорящей о беспомощности, о горькой безнадежности, о тщетности всех стараний в достижении идеального. Постепенно данный мотив переходит в звучание виолончели соло, к которому присоединяются хоральные аккорды в ритме похоронного шествия, будто отпевание мечтаний и желаний героя. Контрапунктом к речитативу и хоральным аккордам становится тема «золотого хода», контуры которой постепенно насыщаются политональными и атональными вкраплениями. В партию виолончели в это время проникают интонации из второй фазы речитатива первой части («монологический хор»). Далее видно как данные тематические комплексы перекликаются, дополняя друг друга и постепенно сводя на нет пульсацию аккорда $c$-moll в траурном шествии.

Следующий этап развития - это имитации на лейтгармонии второй части, представленной здесь в мелодическом виде, в разных временных измерениях. Этот эпизод по принципу воплощения музыкального материала напоминает фрагмент из второй части. Чувство бега по замкнутому кругу (канонические имитации) является предвестником постепенно возникающей темы круга. Ее звучание приобретает более мягкий оттенок, так как она звучит в первой октаве на $\boldsymbol{p}$. Смена регистра и исполнительского штриха - с arco на pizzicato - придает данной остинатной фигуре оттенок траурности. Если при первом появлении тема-круг проходила на фоне тихих педальных кластеров, то, начиная с ц. 8 партия фортепиано звучит в высоком регистре, а контуры мелодического движения правой руки имитационно перекликаются с мотивом circulatio. Это неспешное движение два раза перебивается эмоциональными речитативными всплесками, контрастирующими с предшествующим эпизодом не только в динамическом, но и в фактурном плане. Нисходящее в глубокие басы поступенное мелодическое движение (от $F$ до $B_{1}$ ) приводит к местной репризе, почти без изменений повторяющей начальные одиннадцать тактов. Разница заключается в том, что вместо нисходящей секунды в партии виолончели звучит залигованый звук $c$. Это будто передышка перед кодой части, несущей важную драматургическую нагрузку, так как она (как отмечалось ранее) еще является и кодой всего цикла. 
Начиная с ц. 12 тематический материал в партии виолончели повторяет фрагменты речитативных фраз из первой части, но они звучат на pizzicato, что придает им ирреальные черты. В верхнем голосе застывших квинт и секст виолончели прослушивается рельеф темыкруга, которая в полном виде появляется в высоком регистре фортепиано. Охватывая все больший диапазон, perpetum mobile то высоко взлетает, то спускается, постепенно замирая, в басы. Далее, в единовременном контрасте, звучат тема «золотого хода» и аккомпанемент гротескного вальса из второй части. Уменьшенный септаккорд постепенно истаивает, оставляя после себя лишь ходы marcato по терциям (начало второй части). С ц. 13 и до конца сонаты в контроктаве в партии фортепиано звучит $c-$ сначала повторяющееся в каждом такте, а потом и педализированное.

В последних тактах произведения вновь проходит тема perpetum mobile, звучащая на фоне комплекса $c-c i s-f i s-$ однажды взятого и педализированного. Его отзвук продолжается еще целых девять тактов, заполненных механическим движением темы-круга в заоблачных высотах, уходящей в результате в бесконечную даль.

Обобщая вышесказанное, определяющими композиционно-драматургическое и образно-смысловое своеобразие сонаты можно назвать следующие черты:

- цикличность с тенденцией слияния в одночастность;

- развернутость и самостоятельность инструментальных партий сонаты, что свидетельствует об их паритете. Кроме того, наличие достаточного количества эпизодов (во всех трех частях сонаты), в которых инструменты меняются музыкальным материалом, характерным для каждого до этого момента, говорит о своеобразной попытке «заговорить на языке другого, чтобы приблизиться», что является одной из отличительных черт камерно-инструментальных произведений А. Шнитке в целом;

- стремление к интонационному единству цикла за счет опоры на основополагающие тематические элементы, среди которых: 1) речитативная каденция виолончели, начинающая сонату и пронизывающая всю ее музыкальную ткань, ассоциирующаяся с авторским высказыванием; 2) квазицитата, воспроизводящая историко-стилистическую модель прошлого - тема «золотого хода валторн», которая выступает в композиции сонаты в качестве «чужого слова»; 3) хоральность как концентрация консонантной сферы, которую А. Шнитке понимает как запредельное звучание голоса; 4) тема-круг, для кото- 
рой характерны секундовые интонации, структурная симметрия, ротационный тип мелодики, что придает теме сходство с музыкальнориторической фигурой circulatio. В сонате данная фигура реализуется в мотиве perpetum mobile, построенном по типу развивающейся спирали, постепенно охватывающей все больший диапазон. Совпадение фигур креста и круга в этом мотиве свидетельствует о семантической многослойности этой темы. Знаменательно, что данный факт в очередной раз раскрывает нам диалогичность мышления А. Шнитке. С одной стороны, тема-круг символизирует идею бесконечности и, одновременно, замкнутости бытия, с другой стороны - хоральный вид темы-креста означает направленность к высокой цели, к позитивному духовному результату;

- наделение тематическим значением пауз, что проявляется, в частности, в использовании идеи внезапных пауз. Пауза в сонате несет драматургическое и тематическое значение. Особо важны, как отмечает А. Шнитке, так называемые «внезапные» паузы. Они возникают при нарастании общего напряжения «до невыносимого состояния», при этом «все застывает совершенно неподвижно с тем, чтобы после этого обрушиться и идти дальше» [5, с. 52].

- музыкальный язык Первой виолончельной сонаты демонстрирует авторское стремление к освобождению от аллюзийности, ассоциативности. Однако композитор не только опирается на игру мажоро-минора, но и применяет принцип цитирования, трактованный автором здесь как «цитирование техники» (термин А. Шнитке), что видно на примере аккорда $g$-moll, принадлежащего тональной технике, золотого хода валторн с ладовой перекраской, сохранения значимости тонального центра композиции $-c$-moll.

В целом же организацию данного произведения отличает внутренняя сопряженность всех тематических элементов. Создавая из мозаики разнородных мотивов естественные последования, А. Шнитке, столь же естественно, превращает близкие по исходным формулам мотивы в разнородные. Однако этот калейдоскоп движения и завораживающая стихия преобразований, прежде всего, интригует своей «незаметностью». В этом комбинировании и сопоставлении разнообразных мотивов происходит своего рода «взаимозаменяемость» экспозиционных соотношений, что позволяет говорить об использовании композитором метода стилистической контаминации. 


\section{СПИСОК ЛИТЕРАТУРЫ}

1. Грибиненко Ю. Музыкальная полистилистика в свете теории интертекстуальности : дисс. ... канд. иск. : 17.00.03./Юлия Александровна Грибиненко. - Одеса, 2005. - 198 с.

2. Савенко С. Портрет художника в зрелости / С. Савенко // Советская музыка. - 1981. - № 9. - С. 35-46.

3. Сумарокова Н. Соната-метафора (к проблеме интерпретации виолончельной сонаты А. Шнитке) / Н. Сумарокова // Научный вестник НМАУ им. П. И. Чайковского. - К., 2000. - Вып. 7. - С. 138-151.

4. Холопова В. Альфред Шнитке: Очерк жизни и творчества / В. Холопова, Е. Чигарева. - М. : Советский композитор, 1990. - 350 с.

5. Шульгин Д. Альфред Шнитке. Беседы с композитором / Д. Шульгин. - М. : Деловая лига, 1993. - 275 с.

6. Шульгин Д. Годы неизвестности Альфреда Шнитке / Д. Шульгин. М., 1993. -138 c.

Грібінєнко Ю. Соната для віолончелі та фортепіано № 1 Альфреда Шнітке в контексті еволюції авторського стилю. Стаття присвячена розгляду образно-смислових, композиційно-драматургічних та жанрово-стильових особливостей першої віолончельної сонати А. Шнітке в контексті еволюції його композиторського мислення. Акцентується увага на драматургічних прийомах, специфіці та діапазоні мовних засобів, на особливостях трактування виражальних можливостей інструментів, на образному ладі твору, як етапного на новому витку еволюції авторського стилю композитора.

Ключові слова: віолончельна соната, А. Шнітке, інтонаційна єдність, моностилістіка, пауза.

Gribinenko G. Sonata for violet and piano № 1 Alfreda Schnitke in the context of evolution author's style. The article is devoted to the consideration of figurative-semantic, compositional-dramaturgic and genre-style features of the first cello sonata A. Schnitke in the context of the evolution of his compositional thinking. Attention is focused on dramaturgic techniques, the specifics and range of linguistic means, on the peculiarities of the interpretation of the expressive capabilities of instruments, on the figurative structure of writing, as a landmark in a new round of evolution of the author's style of the composer.

Keywords: cello sonata, A. Schnitke, intonational unity, monostilistics, pause.

Стаття надійшла до редакції 13.04.2016

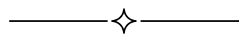

